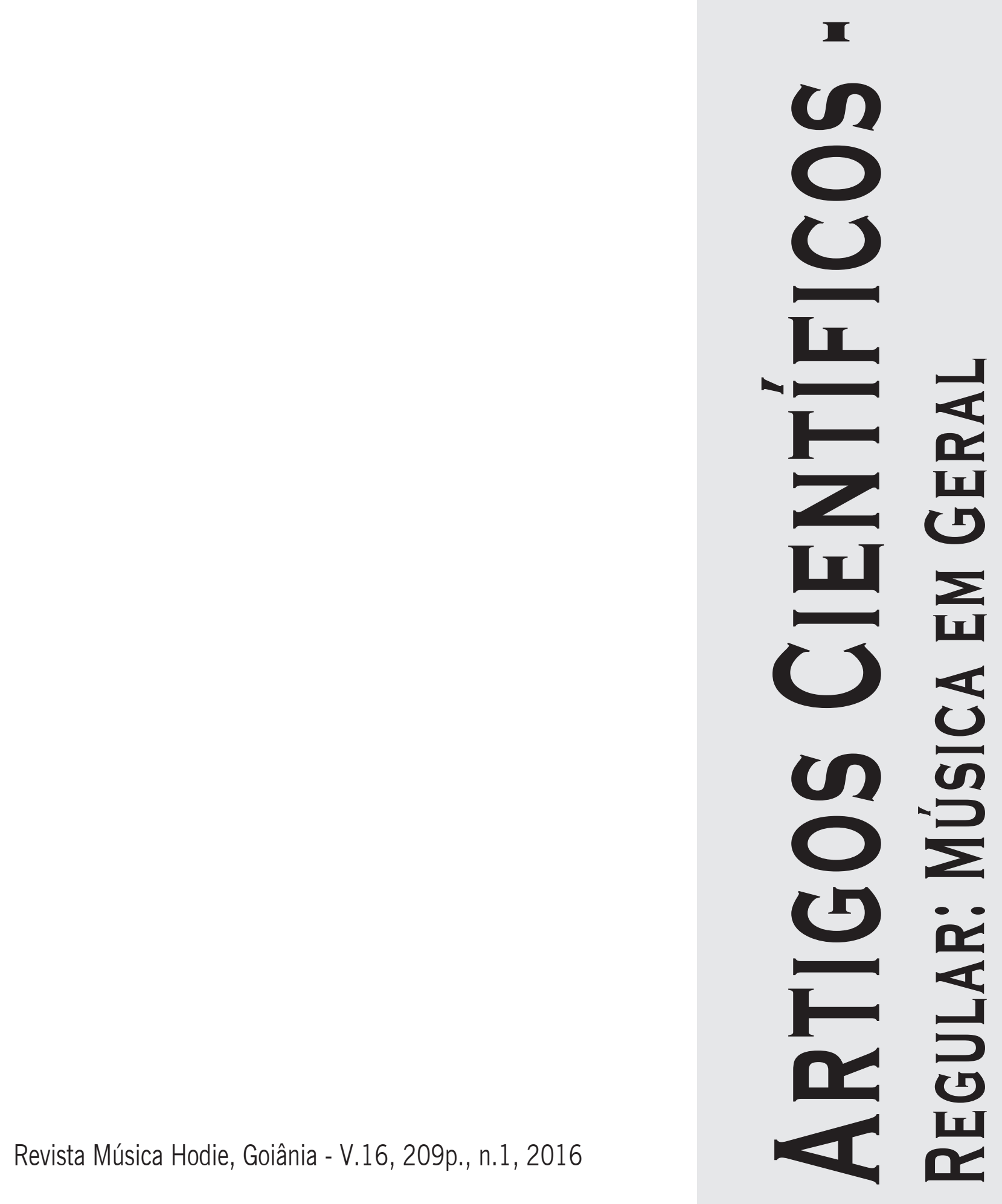




\title{
Música nas escolas: uma investigação sobre a implementação nos municípios do Rio Grande do Sul
}

\author{
Cristina Rolim Wolffenbüttel (Universidade Estadual do Rio Grande do Sul, Montenegro, RS, Brasil) \\ cristina-wolffenbuttel@uergs.edu.br \\ Daniele Isabel Ertel (Universidade Estadual do Rio Grande do Sul, Montenegro, RS, Brasil) \\ dani.ertel@hotmail.com \\ Jusamara Vieira Souza (Universidade Federal do Rio Grande do Sul, Porto Alegre, RS, Brasil) \\ jusa.ez@terra.com.br
}

\begin{abstract}
Resumo: Esta pesquisa investigou a música nas escolas públicas municipais do Rio Grande do Sul. Teve como desenho metodológico a abordagem quantitativa, o método survey interseccional de grande porte e a aplicação de questionários autoadministrados como técnica de coleta dos dados. A análise de conteúdo constituiu a técnica para a análise dos dados, a partir de conceitos da educação musical balizados pela legislação educacional e pela Abordagem do Ciclo de Políticas. Como resultados constatou-se que, apesar da legislação vigente e da existência de algumas atividades musicais nas escolas, ainda persiste a luta para a efetiva implementação da educação musical no estado.
\end{abstract}

Palavras-chave: Música nas Escolas; Políticas Públicas em Educação Musical; Lei Federal nº 11.769/2008.

Music in Schools: a research about the Rio Grande do Sul Municipalities’ Implementation

Abstract: In this research, the way in which music is taught in municipal public schools of Rio Grande do Sul was investigated. The methodological design used included a quantitative approach, an intersectional survey method at large scale, and self-administered questionnaires for collecting data. In order to analyse the data, a content analysis was performed, taking as reference concepts of music education based on education legislation and the Policy Cycle Approach. As a result, it was found that in spite of the applicable law and the existence of some music activities in schools, there is still a struggle for effectively implementing music education in the state.

Keywords: Music in Schools, Public Policies on Music Education, Federal Law N. 11.769/2008.

Música en las Escuelas: una investigación sobre la aplicación em los municípios del Rio Grande do Sul

Resumen: Mediante esta investigación se analizó la forma en que se enseña música en las escuelas públicas municipales de Rio Grande do Sul. El diseño metodológico utilizado incluyó un enfoque cuantitativo, un método de encuesta intersectorial a gran escala y cuestionarios autoadministrados como técnica de recolección de datos. Con el fin de analizar estos datos, se llevó a cabo un análisis de contenido, a partir de los conceptos de educación musical con base en la legislación educativa y el enfoque del ciclo de políticas. Como resultado se observó que a pesar de la legislación vigente y de la existencia de algunas actividades musicales en las escuelas, aún continúa la lucha para que la educación musical se implemente de manera eficaz en el estado.

Palabras clave: Música en las escuelas; políticas públicas sobre educación musical; Ley Federal nº 11.769/2008.

\section{Introdução}

A Educação Musical no Brasil possui uma longa trajetória histórica. Conforme Lemos Júnior (2012):

Os primeiros indícios sobre o ensino da música no Brasil coincidem ao período do descobrimento, especialmente após a chegada dos jesuítas de Portugal. Nesse período, nota-se que a música servia como ferramenta de transmissão da religião e da cultura europeia aos índios brasileiros. Na ocasião a educação musical estava voltada ao modo europeu de promover a educação e a prática musical em igrejas, conventos e colégios. (LEMOS JÚNIOR, 2012, p. 68)

Com a vinda da Família Real, em 1808, o acesso à música foi ampliado, notadamente nos teatros. Porém, mesmo estando presente desde o descobrimento, a música foi oficial- 
mente instituída nas escolas brasileiras somente em 1854, e a formação específica do professor de música exigida apenas em 1890 (LEMOS JÚNIOR, 2012).

Apesar das exigências legais de 1890, não houve o fortalecimento da educação musical escolar. A partir da década de 1920 é que algumas contribuições favoreceram a expansão do ensino de música no país, com a Escola Nova, destacando-se o Canto Orfeônico de Villa-Lobos (LEMOS JÚNIOR, 2012).

As reformas realizadas no ensino brasileiro em 1931 e em 1942 oportunizaram a expansão do Canto Orfeônico, tornando-o obrigatório no ensino primário e ginasial. O início da ditadura militar, em 1964, fez necessária uma adequação à educação brasileira como um todo, ocorrendo diversas mudanças, como a modificação do nome Canto Orfeônico para Educação Musical. Em 1971, o ensino de música foi extinto dos currículos escolares, passando a ser denominado de Educação Artística, e mantendo um caráter interdisciplinar, com ênfase nas Artes Plásticas, Dança, Música e Teatro (LEMOS JÚNIOR, 2012).

Nesta época, com a Lei de Diretrizes e Bases da Educação Nacional n ${ }^{0}$ 5.692, de 1971 (LDB 5.692/71), foi instituído o ensino da Educação Artística no Ensino Fundamental e Médio de todo o país (BRASIL, 1971). A partir da LDB 5.692/71 os conteúdos específicos das linguagens artísticas, principalmente a Música, foram esvaziados, em prol de uma educação dita polivalente. Para Hentschke e Oliveira (2000), na década de 1970 predominava a tendência educacional cuja ênfase apresentava-se mais no aspecto expressivo dos indivíduos. A atenção no processo de ensino e aprendizagem destinava maior ênfase no processo, ao invés do produto, não considerando a abordagem relativa à formação de artistas. Como consequência,

a postura técnica do professor era, então, de atender às orientações gerais do programa, flexibilizando horários, avaliações, seleção de alunos para determinadas atividades, evitando o ensino de técnicas artísticas e musicais e concentrando as atividades na expressão em várias modalidades artísticas. (HENTSCHKE; OLIVEIRA, 2000, p. 48)

Nesta perspectiva, Penna (2004a, 2004b) investigou a política educacional para o ensino das artes no Ensino Fundamental e Médio da Educação Básica, analisando os documentos oficiais e as implicações dos mesmos para as práticas escolares. A pesquisadora analisou a legislação e os termos normativos do ensino de música, apontando as continuidades e as modificações ocorridas entre as décadas de 1970 e 1990 (PENNA, 2004a). A autora discutiu a política educacional para o ensino das artes, a partir da análise da LDB $\mathrm{n}^{\circ}$ 5.692/71 (BRASIL, 1971) e, posteriormente, do Parecer do Conselho Federal de Educação n ${ }^{o}$ 1.284, de 1973 (BRASIL, 1973). O referido parecer propunha o ensino das artes na Educação Básica em uma perspectiva integrada, na proposta de polivalência dos professores quanto às Artes Plásticas, Artes Cênicas, Música e Desenho. Segundo Penna (2004a), não havia uma definição clara no texto da LDB 5.692/71 a respeito de quais linguagens artísticas deveriam ser contempladas. No artigo $7^{\circ}$ da LDB 5.692/71 encontra-se o estabelecimento das diretrizes e bases para o ensino de $1^{\circ}$ e $2^{\circ}$ graus, aparecendo a obrigatoriedade da Educação Artística, sem especificar o ensino de Música ou de outra área das Artes (BRASIL, 1971).

Posteriormente, o Parecer CFE $n^{0}$ 540/77 apontou uma inadequação de enfoque na área, ocorrida em anos anteriores, afirmando que, nessa época, o ensino de Música centrava-se, apenas, na teoria musical e na prática do canto coral, sendo que o ensino da Educação Artística não mais comportaria tais abordagens. Sob esse aspecto, portanto, e considerando uma integração entre as áreas artísticas, a Música encontrar-se-ia no campo da Educação Artística (BRASIL, 1977b). 
Ao longo dos anos, os esforços foram intensificados, no sentido de tornar mais específicos os preceitos normativos para o ensino de música, evidenciado nos pareceres do Conselho Federal de Educação dos anos 1973 e 1977 (PENNA, 2004a). A Lei de Diretrizes e Bases da Educação Nacional no 9.394, de 1996 (LDB 9.394) é, também, resultado da busca pela separação no ensino das Artes na Educação Básica (BRASIL, 1996).

Apesar de a LDB no 9.394/96 estabelecer o ensino das Artes como componente curricular obrigatório nos diversos níveis da Educação Básica, persistiu a indefinição e a ambiguidade (PENNA, 2004a), o que permitiu o surgimento de múltiplas possibilidades, na medida em que o ensino das Artes poderia ser interpretado de diversos modos (BRASIL, 1996).

A partir da LDB 9.394/96, pesquisadores lutaram para separar as áreas das Artes no ensino escolar. Apesar das mudanças efetuadas na legislação, na prática, o ensino ainda continuava a ser denominado de Educação Artística. Desde então, os estudos e as pesquisas têm buscado um entendimento maior a respeito do ensino de Música escolar e das políticas públicas para o ensino de Música na Educação Básica (WOLFFENBÜTTEL, 2014; QUEIROZ, 2013, REQUIÃO, 2013; QUEIROZ; PENNA, 2012; WOLFFENBÜTTEL; ERTEL, 2011; DEL BEN, 2005; DINIZ, 2005; SANTOS, 2005; PENNA, 2002, 2004a, 2004b; SOUZA et al, 2002). Mesmo com as tentativas para garantir a presença do ensino de Música na Educação Básica, as políticas mais recentes não têm conseguido legitimar esse esforço. Pesquisadores têm constatado a escassa presença de professores de música atuando na Educação Básica (WOLFFENBÜTTEL; SILVA, 2014; WOLFFENBÜTTEL, 2011; PENNA, 2014, 2002, 2004a, 2004b; SANTOS, 2005; DEL BEN, 2005). Nesse sentido, algumas ações foram empreendidas para oportunizar a presença de atividades musicais nas escolas. Um desses empreendimentos caracterizou-se por ações musicais desenvolvidas através Programa Mais Educação ${ }^{1}$ (PENNA, 2014; VEBER, 2012). As práticas pedagógicas em música desenvolvidas em oficinas desse programa em escolas paraibanas, por exemplo, foram investigadas por Penna (2014). A autora constatou que, embora o Programa Mais Educação contribua para a realização de atividades musicais nas escolas, ainda há desafios a serem ultrapassados.

Com a Lei $\mathrm{n}^{\mathrm{O}}$ 11.769, de 2008 (BRASIL, 2008), que dispõe sobre a obrigatoriedade do ensino da Música na Educação Básica, o panorama legal para essa inserção, nas escolas, recebeu um incremento. De acordo com alei, a obrigatoriedade deveria entrar em vigor na data de sua publicação, em 19 de agosto de 2008, e os sistemas de ensino teriam três anos letivos para se adaptarem às exigências estabelecidas, ou seja, em 2011. Passaram-se os anos e observou-se que muitas das secretarias de educação do país não implementaram a Música nas escolas de suas redes de ensino.

Em 2013, o Conselho Nacional de Educação (CNE) realizou audiências públicas, em parceria com a Associação Brasileira de Educação Musical (ABEM), para discutir o assunto com a sociedade e construir uma resolução. Estas ações resultaram no Parecer CNE/CEB no 12/2013 (BRASIL, 2013), aprovado em 4 de dezembro de 2013, e definido através da Resolução $\mathrm{n}^{\mathrm{o}}$ 2, de 10 de maio de 2016 (BRASIL, 2016). As ações do CNE produziram efeitos em alguns municípios brasileiros. No RS observou-se a movimentação de algumas prefeituras que lançaram editais de concursos para professores de Música. Não obstante, estas ações ainda não foram suficientes.

Partindo desses pressupostos e da legislação vigente, surgiram questionamentos em relação à inserção da música nas escolas públicas municipais do Rio Grande do Sul, sendo esses: Quantas secretarias municipais de educação do Rio Grande do Sul implementaram a Música nas escolas de suas redes de ensino? Quantas e quais secretarias municipais de educação do estado ofertam atividades musicais? Quais são as ações de inserção da Mú- 
sica nas escolas? Quem desenvolve atividades musicais nas escolas públicas municipais? Quantas e quais secretarias municipais de educação promoveram concursos para professores de Música? Quantas e quais secretarias municipais de educação possuem professores de Música concursados em suas redes de ensino? Esta pesquisa, portanto, objetivou investigar a presença do ensino da Música em escolas públicas municipais do Rio Grande do Sul.

\section{Caminhos metodológicos}

A metodologia desta pesquisa foi balizada pela abordagem quantitativa, pelo método survey (COHEN; MANION, 1994; BABBIE, 1999) e pela aplicação de questionários autoadministrados como técnica para a coleta dos dados (LAVILLE; DIONE, 1999).

A coleta dos dados ocorreu através de contatos via correio eletrônico com as secretarias municipais de educação dos 497 municípios que compõem o RS. Nesses contatos foram encaminhados uma carta de apresentação da pesquisa e da equipe executora, bem como um questionário do tipo misto (MARKONI; LAKATOS, 2005). O questionário, formado por 12 questões de respostas abertas e fechadas, inquiria as secretarias municipais de educação sobre a oferta de atividades musicais nas escolas, a respeito das atividades musicais existentes nas escolas, sobre a promoção de concursos públicos para professores de Música, questionava sobre a presença de professores de Música nas escolas, bem como sobre os profissionais que desenvolvem atividades musicais nas escolas. Este questionário foi, também, enviado às secretarias municipais de educação do RS, sendo solicitado seu preenchimento e o posterior retorno via e-mail. De posse dos questionários respondidos procedeu-se à análise de conteúdo, trilhando as etapas de preparação das informações, unitarização, categorização, descrição e interpretação (MORAES, 1999).

Com os dados coletados - através dos questionários autoadministrados - estes passaram pelo processo de preparação, identificando amostras de informação a serem analisadas. Esse procedimento ocorreu a partir da leitura dos dados no todo, procedimento seguido da seleção de questionários que estavam de acordo com os objetivos da pesquisa. Devidamente preparados, os dados passaram pela unitarização, através da leitura de todo o material e da definição da unidade de análise. Em seguida, o material foi relido, sendo identificadas as unidades de análise e codificando-as, passando-se à categorização. Esses procedimentos prepararam a descrição. Definidas as categorias e identificado o material de cada uma delas, passou-se à comunicação dos resultados, cuja descrição é o primeiro momento. Para cada categoria foi produzido um texto-síntese inicial sobre a música nas escolas de cada município. Esse procedimento subsidiou a interpretação (MORAES, 1999).

Por fim, realizou-se a interpretação, fundamentada na literatura especializada e demais experiências da investigação, além daquelas vividas durante a pesquisa. Foi constituída de duas vertentes; uma delas, formada pela fundamentação teórica em Educação Musical (KRAEMER, 2000) e pela análise das políticas - notadamente a Abordagem do Ciclo de Políticas (BOWE et al, 1992; BALL, 1994). A outra vertente tomou por base os dados e as categorias da análise. Os resultados e as discussões emergiram dos dados e das categorias. Neste caso, a própria construção da teoria foi a interpretação. Teorização, interpretação e compreensão constituíram-se um movimento circular em que se procurou, a cada retomada do ciclo, atingir maior profundidade na análise (MORAES, 1999). Ao final das cinco etapas - preparação, unitarização, categorização, descrição, interpretação - respondeu-se ao objetivo desta pesquisa, ou seja, investigar a presença do ensino da Música em escolas públicas municipais do Rio Grande do Sul. 


\section{Fundamentação teórica}

O referencial teórico da pesquisa fundamentou-se em conceitos de educação musical (KRAEMER, 2000) balizados pela Abordagem do Ciclo de Políticas (BOWE et al, 1992; BALL, 1994).

\subsection{A educação musical}

Kraemer (2000) trata da educação musical como um imbricamento entre disciplinas, discutindo dimensões e funções do conhecimento pedagógico-musical e salientando as particularidades da área em relação às demais disciplinas. O autor esclarece que a pedagogia da música se ocupa com as relações entre pessoa(s) e música(s), dividindo seu objeto de estudo com as ciências humanas. Kraemer (2000) exemplifica essas disciplinas enfocando-as quanto aos aspectos filosóficos, históricos, psicológicos, sociológicos, musicológicos, pedagógicos e de outras disciplinas que possam ter um significado pedagógico-musical importante.

Os aspectos filosóficos, apontados por Kraemer (2000), incluem a estética da música e a antropologia pedagógica. Os aspectos históricos são tratados na perspectiva de que, sendo a história um conjunto de contribuições humanas, é importante que as pessoas reconstruam seus próprios acontecimentos a partir do material disponível, analisando-os e os interpretando criticamente. Assim, a história abrangeria a pesquisa e a escrita histórica. O autor salienta, nessa análise, a musicologia histórica e a pedagogia histórica.

Dentre os aspectos psicológicos, Kraemer (2000) apresenta a psicologia geral da música - recepção estética e sociológica da música, pesquisa sobre aprendizagem e motivação - a psicologia da música psicológico-social - socialização musical, pesquisas sobre concepção musical e sobre comunicação - a psicologia diferenciada da música - talento musical e sua medição, desenvolvimento de testes, características da personalidade e do comportamento musical - e a psicologia do desenvolvimento - gênese de determinados comportamentos musicais e níveis de vivência relativos ao amadurecimento, crescimento e meio sociocultural.

Os aspectos sociológicos partem da sociologia da música, examinando seus efeitos, e as condições e relações sociais relacionadas à música. O homem é observado nas áreas institucionalizadas e organizadas da educação, incluindo "processos de socialização, instituições e formas de organização, profissão, grupos de mesma idade, meios e condições legais e econômicas” (KRAEMER, 2000, p. 57).

Pedagogia da música e musicologia "unem-se no esforço comum em compreender a música”. Os aspectos musicológicos são apresentados considerando-se a pesquisa musicológica - etnomusicologia, acústica, teoria da música, entre outras áreas - tratando de uma "possível análise e interpretação global dos eventos musicais", sendo o conteúdo musical propriamente dito (KRAEMER, 2000, p. 58-59). A didática da música interessar-se-ia pelos significados que as manifestações musicais poderiam adquirir no processo educacional.

Os aspectos pedagógicos partem da pedagogia, que se ocupa "com teorias da educação e formação, premissas, condições, processos e consequências da ação educacional e didática, com questões sociais e institucionais, com problemas do ensino, da aprendizagem e didáticos” (KRAEMER, 2000, p. 59). São apontados diferentes ramos da pedagogia como ciência da educação: pedagogia geral, pedagogia especial, pedagogia histórica, pedagogia pré-escolar, pedagogia escolar, pedagogia da família, pedagogia social, pedagogia da empre- 
sa/profissão/economia e pedagogia comparada. Há outras disciplinas que podem apresentar um significado pedagógico-musical especial, como ciências políticas, pedagogia do esporte, pedagogia da arte, questões medicinais e de saúde, jurídicas, pedagógico-religiosas, ecológicas, econômicas, para citar algumas das possibilidades existentes (KRAEMER, 2000).

Kraemer (2000) discute o entrelaçamento da pedagogia da música com outras disciplinas. Rassalta-se que uma perspectiva de entrelaçamento da área considera-a como resultante do enlace recíproco entre as disciplinas, criando uma espécie de teia. Essa concepção de entrelaçamento propõe uma dimensão alargada da área, com limites mais abrangentes e flexíveis.

Para Kraemer (2000), no "centro das reflexões musicais estão os problemas da apropriação e transmissão da música” (p. 61). Pedagogia e pedagogia da música não se constituem disciplinas isoladas e resultam diferentes agrupamentos da área. São disciplinas de integração orientadas na ação, conforme o objeto de pesquisa. Kraemer (2000) afirma que a particularidade do saber pedagógico-musical está "no cruzamento de ideias pedagógicas marcadas pelas ciências humanas, orientadas pela cultura musical e ideias estético-musicais" (p. 66). Além do conhecimento sobre fatos e contextos pedagógico-musicais, também é necessário colocar à disposição os princípios de explicação da prática músico-educacional, para as decisões, orientações, esclarecimentos, influência e otimização dessas práticas,

Por fim, Kraemer (2000) propõe um modelo estrutural da pedagogia da música, o qual inclui a análise e os campos de aplicação da área, os aspectos que a compõem - musicológicos, pedagógicos, entre outros - além das funções da pedagogia da música - compreender e interpretar, descrever e esclarecer, conscientizar e transformar a prática músico-educacional.

\subsection{A abordagem do ciclo de políticas}

A caracterização do processo político foi proposta por Bowe et al (1992) e Ball (1994), o que veio a subsidiar a elaboração da Abordagem do Ciclo de Políticas. Para os autores, ao introduzir a noção de um ciclo contínuo de política, a pretensão objetivava atrair a atenção para a recontextualização política que transita pelas escolas. Contudo, o panorama das pesquisas escolares requer considerar não somente um currículo nacional, mas também outros elementos que constituem a política educacional (BOWE et al, 1992). Há um ciclo composto de contextos que influenciam e são influenciados, sendo estes o contexto da influência, o contexto do texto político, o contexto da prática, o contexto dos efeitos e o contexto da estratégia política.

O contexto em que a política é iniciada, no qual os discursos políticos são construídos e as partes interessadas lutam para influenciar as decisões, é o da influência. O segundo contexto, do texto político, constitui-se de textos representativos da política. Essas representações podem se apresentar como textos jurídicos, documentos oficiais orientadores, comentários formais ou informais, discursos, apresentações públicas de políticos e funcionários importantes, vídeos oficiais, entre outras representações (BOWE et al, 1992). Políticas são, portanto, intervenções textuais; contudo, elas também carregam consigo limitações e possibilidades. A resposta a esses textos tem consequências reais, as quais são experienciadas no contexto da prática. Esse contexto constitui-se a arena da prática, a quem a política se dirige. A política não é simplesmente recebida e implementada neste cenário, mas está sujeita à interpretação, podendo ser recriada. As pessoas que executam as políticas não se confrontam ingenuamente com os textos políticos (BOWE et al, 1992). 
Posteriormente, Ball (1994) expandiu a teoria, acrescentando dois contextos: o contexto dos efeitos e o contexto da estratégia política. O contexto dos efeitos preocupa-se com as questões de justiça, igualdade e liberdade individual. Os efeitos das políticas apresentam-se como efeitos gerais e específicos. Os efeitos gerais de uma política são quando aspectos específicos da mudança e conjuntos de respostas - que se apresentam no contexto da prática - são agrupados e analisados. Os efeitos gerais das políticas são, por vezes, negligenciados em estudos mais particularizados em relação às mudanças ou os textos políticos como determinantes do impacto na prática. Se analisados isoladamente, os efeitos específicos podem parecer limitados. Ball sugere, então, que a análise de uma política envolva o exame dessas duas dimensões, bem como das interfaces da política em estudo com outras políticas setoriais e com o conjunto das políticas. Por fim, o contexto da estratégia política envolve a identificação de um conjunto de atividades sociais e políticas necessárias para o trato com as desigualdades originadas pela política em estudo. Esse componente é essencial para a pesquisa social crítica, e esse trabalho é produzido para uma utilização estratégica em embates e situações sociais específicas (BALL, 1994).

Ball (1994) postula a necessidade de desvincular as teorias em política educacional dos trabalhos do Estado. A política é uma “economia de poder”, um conjunto de tecnologias e práticas, cujas realizações e lutas ocorrem acima dos arranjos locais. Política é, ao mesmo tempo, texto e ação, palavras e contratos; isso é o que se representa e o que se pretende. Políticas são sempre incompletas, básicas e simples. A prática, todavia, é sofisticada, contingente, complexa e instável. A política como prática é criada em uma "trialética" de dominação, resistência e caos/liberdade. Então, a política não é simplesmente uma assimetria de poder. O controle ou a dominação nem sempre podem ser totalmente seguros ou tranquilos, em parte devido à agência.

Entende-se, portanto, que a Abordagem do Ciclo de Políticas não pretende minimizar ou subestimar os efeitos ou impactos das políticas, mas problematizar todo o processo subjacente à proposta da abordagem (BALL, 1994).

\section{Resultados e discussões}

A partir da organização e tabulação dos dados, os mesmos foram analisados à luz da fundamentação teórica apresentada anteriormente, tendo por técnica para a análise, a análise de conteúdo, proposta por Moraes (1999).

De posse de todos os dados, os mesmos foram organizados em seis categorias de análise, quais sejam: as secretarias municipais de educação da pesquisa, a oferta de atividades musicais nas escolas, as atividades musicais existentes nas escolas, a promoção de concursos públicos para professores de música, a presença de professores de música nas escolas e os profissionais que desenvolvem atividades musicais nas escolas.

\subsection{As secretarias municipais de educação da pesquisa}

Os dados de identificação informados nos questionários permitiram identificar quantas e quais secretarias municipais de educação do RS retornaram o questionário respondido. Dos 497 municípios existentes no estado, 270 responderam à pesquisa, o que soma 54,32\%. 
À época da coleta dos dados (2015), o número total de escolas existentes no estado somava $5.030^{2}$. Destas, foram obtidas informações - através das secretarias municipais de educação - de 1.612 escolas. Ao todo, as informações apresentadas nesta pesquisa perfazem 32,04\% das escolas públicas municipais do Rio Grande do Sul, o que se apresenta com um índice aceitável de retorno em se tratando de pesquisa, pois, de acordo com Marconi e Lakatos (2005), questionários que são enviados para os entrevistados alcançam em média $25 \%$ de devolução.

Os resultados apresentados e as discussões deste artigo, portanto, baseiam-se neste retorno.

\subsection{A oferta de atividades musicais nas escolas}

A partir dos dados da pesquisa constatou-se que 219 secretarias municipais de educação oferecem a Música nas escolas de sua rede de ensino. Este número perfaz 81,11\% do total de respondentes. É um índice significativo, pensando-se na quantidade de escolas que ofertam a Música. Todavia, não é possível fazer uma análise abrangente, pois este dado relaciona-se aos 270 municípios respondentes, dentre os 497 existentes no estado.

Para aprofundar a análise deste dado, pode-se pensar que o não retorno dos questionários das 227 das secretarias municipais de educação - que, na soma com os 270 questionários retornados resulta 497, o número de municípios e de secretarias municipais de educação do RS - pode ser justificado pela não oferta de atividades musicais nas escolas das redes de ensino das secretarias não respondentes. Se este for o modo de analisar, então, o percentual diminui para 44,04\%.

Partindo-se deste último número - 44,04\% - analisa-se o mesmo como um baixo índice. Corrobora a análise o fato de existir no Brasil, desde o ano de 2008, uma legislação nacional que dispõe sobre a obrigatoriedade da Música na Educação Básica - a Lei $\mathrm{n}^{\circ}$ 11.769/2008. Esta lei tem abrangência nacional e, portanto, deveria ser cumprida em todos os estados e municípios do país.

Este dado é preocupante em se tratando da inserção da música nas escolas do RS. Como análise pode-se pensar na perspectiva do contexto da prática, proposto na Abordagem do Ciclo de Políticas. Conforme Bowe et al (1992), é no contexto da prática que a política está sujeita à interpretação e recriação. É neste contexto que a política produz efeitos que podem representar mudanças e transformações. Neste sentido e, concordando com os autores, observa-se que a legislação para a inserção da Música nas escolas do RS não foi simplesmente "implementada", mas esteve sujeita à interpretação (BOWE et al, 1992). A partir da análise dos dados observou-se que diversas secretarias municipais de educação recriaram a lei, entendendo que a obrigatoriedade para a Educação Básica seja a presença da Arte - particularmente as Artes Visuais ou, até, a Educação Artística, extinta com a LDB 9.394/96 e não a Música. Desse modo, o que pensam e o que acreditam os profissionais que têm um papel ativo e primordial no processo de interpretação e reinterpretação das políticas educacionais - neste caso, os gestores das secretarias municipais de educação, para o cumprimento da Lei Federal no 11.769/2008 - tem implicações diretas para o sucesso ou insucesso no processo de implementação das políticas educacionais. 


\subsection{As atividades musicais existentes nas escolas}

As atividades musicais existentes nas escolas da rede pública municipal do RS são diversificadas. As respostas para esta questão foram encaminhadas por $27,77 \%$ das secretarias municipais de educação. Em 72,23\% dos questionários não houve retorno para esta questão. De acordo com suas respostas, de um modo geral, constatou-se que existem atividades musicais como canto coral, bandas, aulas de instrumentos musicais, aulas de Música dentro da disciplina de Educação Artística, Música integrada às outras disciplinas, atividades esporádicas de Música para preparação de festividades, promoções eventuais de festivais de música ou amostras de arte com Música e aulas de Música como disciplina específica - separada da disciplina de Educação Artística. A Tabela 1, apresenta as atividades musicais e suas incidências.

Tabela 1: Atividades Musicais Existentes nas Escolas da Rede Pública Municipal de Ensino.

\begin{tabular}{|l|c|}
\hline \multicolumn{1}{|c|}{ Tipo de Atividade Musical } & $\%$ \\
\hline Atividades extracurriculares (canto coral, bandas, aulas de instrumentos musicais). & $58,51 \%$ \\
\hline Aulas de música na disciplina de Educação Artística. & $39,25 \%$ \\
\hline Atividades com música, integradas às demais disciplinas. & $39,25 \%$ \\
\hline Atividades esporádicas de música para preparação de festividades. & $27,77 \%$ \\
\hline Promoções eventuais de festivais de música ou amostras de arte com música. & $20,74 \%$ \\
\hline Aulas de música como disciplina específica (separada da disciplina de Educação Artística). & $15,95 \%$ \\
\hline
\end{tabular}

Fonte: Cristina Rolim Wolffenbüttel.

Além destas atividades, em 31\% das respostas das secretarias municipais de educação foram encontradas outras modalidades de oferta para as atividades musicais nas escolas. Esses 31\% dividem-se em oficinas extracurriculares de Música, aulas de instrumentos musicais, atividades musicais oportunizadas através do Programa Mais Educação, banda marcial, festivais de Música e apresentações públicas, aulas na Educação Infantil e séries/ anos iniciais, atividades musicais oportunizadas através do Programa Escola Aberta ${ }^{3}$ e oficinas de Música para alunos e professores. A Tabela 2, apresenta as outras atividades musicais existentes nas escolas.

Tabela 2: Outras Atividades Musicais Existentes nas Escolas da Rede Pública Municipal de Ensino.

\begin{tabular}{|l|c|}
\hline \multicolumn{1}{|c|}{ Tipo de Atividade Musical } & $\%$ \\
\hline Oficinas extracurriculares de música. & $42 \%$ \\
\hline Aulas de instrumentos musicais. & $31 \%$ \\
\hline Atividades musicais no Programa Mais Educação. & $24 \%$ \\
\hline Banda marcial. & $21 \%$ \\
\hline Festivais de música e apresentações públicas. & $11 \%$ \\
\hline Aulas na Educação Infantil e Séries/Anos Iniciais. & $5 \%$ \\
\hline Atividades musicais no Programa Escola Aberta. & $2 \%$ \\
\hline Oficinas de música para alunos e professores. & $1 \%$ \\
\hline
\end{tabular}

Fonte: Cristina Rolim Wolffenbüttel.

Uma análise sobre as atividades musicais existentes nas escolas da rede pública de ensino do RS pode ser feita a partir de conceitos da educação musical, considerando-se o que postula Kraemer (2000). De acordo com o autor, a educação musical dar-se-á na relação 
entre as pessoas e as músicas. Se a análise se der levando em consideração os 58,51\% dos respondentes que revelaram os tipos de atividades musicais que existem, como participação em grupos de canto coral, bandas, dentre outras atividades extracurriculares - que não a Música como disciplina inserida no currículo - pode-se considerar que a educação musical esteja ocorrendo nestes municípios, servindo para o cômputo da existência do ensino de Música nas escolas da rede pública municipal de ensino no RS.

Mas, outras duas ponderações podem ser feitas. Uma delas, relativa à educação musical, e a outra que remete, novamente, à Abordagem do Ciclo de Políticas. Quanto à educação musical, sim, se há atividades musicais nas escolas, envolvendo estudantes e músicas em relação ao ensino e à aprendizado, então, a educação musical está acontecendo. Entretanto, é importante pensar, também, que, se a Música na escola ocorrer predominantemente como atividade extracurricular, um questionamento pode ser feito: Quando será possível, efetivamente, inserir a Música nas escolas de modo amplo, possibilitando interlocuções com as demais áreas e, assim, contribuindo efetivamente com o processo de educação escolar? Entende-se a importância de a Música encontrar-se em diversos tempos e espaços da escola. Mas, entende-se também, que é importante estabelecê-la como uma das disciplinas integrantes do currículo da Educação Básica. E, mesmo que no contexto da prática, cada vez mais seja possível este estabelecimento, nada garante a continuidade dessa existência, considerando-se a longa trajetória história da educação musical no Brasil, com suas idas e vindas, inserções e exclusões, desde o século XIX, como apresentado na introdução deste artigo.

Esta perspectiva de análise liga-se à segunda ponderação. Se a Música ficar restrita às atividades extracurriculares da escola corre-se o risco de que ela fique, apenas, neste tempo e espaço escolar - novamente, pois esta situação já ocorreu na longa história da educação musical escolar no Brasil. Desse modo, o contexto da prática - caracterizado pela crescente legitimação da música como extracurricular - propiciará a paulatina ausência da Música como integrante do currículo, consubstanciando-se como algo fora da escola. Desse modo, haverá efeitos - o que se encontra no contexto dos efeitos (BOWE et al, 1992) - fazendo com que, novamente, seja retirada a obrigatoriedade da Música nas escolas. Observa-se, portanto, que, mesmo que sob um ponto de vista, estejamos conceitualmente constatando a presença da Música nos contextos das escolas da rede pública municipal do RS, há que se fazer esta análise com muita ponderação.

Ainda, é importante salientar que toda esta análise se baseia em 27,77\% dos respondentes que apontaram as atividades musicais em suas redes de ensino. Em $72,23 \%$ não houve respostas, o que pode remeter, como analisado anteriormente - no que tange à oferta de atividades musicais nas escolas da rede pública municipal de ensino - que a grande maioria das secretarias municipais de educação do RS não oferta Música em sua rede de ensino, outro dado que revela o descumprimento da legislação nacional vigente em educação.

\subsection{A promoção de concursos públicos para professores de música}

A promoção de concursos públicos para o provimento de cargos de professores de Música foi um dos itens desta pesquisa que se apresentou com índices bastante baixos. A análise pode ser feita, tanto se considerando o número de retornos dos questionários, quanto sem este retorno.

Em uma análise mais superficial, dentre as 270 secretarias municipais de educação que retornaram os questionários, o índice de realização de concursos foi de 18,14\%, ou seja, 49 municípios realizaram concursos para professores de música no RS. As demais 214 
secretarias $(79,25 \%)$ responderam não ter realizado este concurso. Sete secretarias $(2,59 \%)$ não responderam a esta questão. A Tabela 3, sintetiza os dados sobre a promoção de concursos públicos para professores de música.

Tabela 3:Promoção de Concursos Públicos para Professores de Música.

\begin{tabular}{|l|c|}
\hline \multicolumn{1}{|c|}{ Tipo de Atividade Musical } & $\%$ \\
\hline Municípios que não promoveram concursos públicos para professores de música. & $79,25 \%$ \\
\hline Municípios que promoveram concursos públicos para professores de música. & $18,14 \%$ \\
\hline Municípios que não responderam à questão. & $2,59 \%$ \\
\hline
\end{tabular}

Fonte: Cristina Rolim Wolffenbüttel.

O índice de 18,14\% já é bastante baixo, se for considerado que há uma legislação no Brasil que dispõe sobre a obrigatoriedade da Música na escola. Corrobora o fato de que esta lei já deveria estar em vigor desde 2011, e a coleta dos dados desta pesquisa ter sido realizada em 2015. Neste sentido, mesmo após quatro anos do prazo final da lei vigorar, a mesma não tem sido cumprida.

Mas, este quadro agrava-se ainda mais, se a análise for ampliada considerando-se a totalidade de municípios do Rio Grande do Sul, ou seja, o número de 497. Neste caso, temos 49 municípios que realizaram concurso (18,14\%) e 441 que não realizaram, o que perfaz 88,73\% do total. Este número de 441 origina-se das respostas negativas quanto aos concursos por parte de 214 secretarias municipais de educação que retornaram o questionário, somadas às 227 secretarias que não o retornaram, o que pode ser um indício da não existência da Música nas escolas de suas redes de ensino e, por consequência, da não realização de concursos públicos para o ingresso de professores de música. Se quisermos aprofundar mais a análise, então este número de 441 pode ser acrescido de sete (questionários que não continham a resposta a esta questão), resultando 448 municípios (90,14\%) que não realizaram concursos públicos para o provimento de cargos de professores de Música em suas redes de ensino. Os 49 municípios que promoveram os concursos, neste caso, perfazem 9,85\% do total. A análise ampliada da situação da realização destes concursos encontra-se sintetizada na Tabela 4.

Tabela 4: Análise da Ampliação da Promoção de Concursos Públicos para Professores de Música.

\begin{tabular}{|l|c|}
\hline \multicolumn{1}{|c|}{ Tipo de Atividade Musical } & $\%$ \\
\hline Municípios que não promoveram concursos públicos para professores de música. & $90,14 \%$ \\
\hline Municípios que promoveram concursos públicos para professores de música. & $9,85 \%$ \\
\hline
\end{tabular}

Fonte: Cristina Rolim Wolffenbüttel.

Além da análise já realizada remetendo à Abordagem do Ciclo de Políticas, considerando-se os contextos do texto político e o contexto da prática, que podem resultar modificações na legislação e, assim, ser retirada a obrigatoriedade da música nas escolas, há que se considerar, também, a dinâmica necessária à realização de concursos públicos nos municípios brasileiros, sejam eles da natureza que forem, inclusive para professores de Música. De acordo com o item IV, do Artigo 21 da Lei $n^{\circ}$ 6.448, de 11 de outubro de 1977, compete à Câmara Municipal, com a sanção do Prefeito, criar, alterar e extinguir cargos públicos, fixando-lhes os vencimentos (BRASIL, 1977a). Neste sentido, para que um município possa 
realizar concurso público para o provimento de cargos de professores de Música, é necessário que esses cargos, primeiramente, existam. Entende-se que, na maioria dos municípios do RS, estes cargos ainda não estejam previstos. Desse modo, o caminho para a realização de concursos para professores de música é bastante longo, pois a trajetória da criação de leis é lenta no Brasil, e o quadro que se apresenta no RS não é diferente.

\subsection{A presença de professores de música nas escolas}

Considerando-se os 49 municípios - dentre os 497 - que realizaram concursos para professores de Música, observou-se que a maioria teve este procedimento após o ano de 2011, quando findou o prazo para a implantação da Lei $\mathrm{n}^{0} 11.769 / 2008$ - da obrigatoriedade da música nas escolas. Dos municípios que realizaram concursos, 22 (44,89\%) informaram tê-los realizado após o ano de 2011. Outros 12 municípios (24,48\%) responderam já ter promovido concursos para professores de Música antes do ano de 2008. A Tabela 5 completa sobre a realização de concursos públicos para professores de música nos 49 municípios que informaram tê-los realizado é apresentada a seguir:

Tabela 5: Anos de Realização dos Concursos Públicos para Professores de Música pelos Municípios.

\begin{tabular}{|l|c|}
\hline \multicolumn{1}{|c|}{ Tipo de Atividade Musical } & $\%$ \\
\hline Municípios que promoveram concursos públicos para professores de música em 2011. & $44,89 \%$ \\
\hline Municípios que promoveram concursos públicos para professores de música antes de 2008. & $24,48 \%$ \\
\hline Municípios que promoveram concursos públicos para professores de música após 2011. & $18,36 \%$ \\
\hline Municípios que promoveram concursos públicos para professores de música após 2010. & $6,12 \%$ \\
\hline Municípios que promoveram concursos públicos para professores de música após 2008. & $2,04 \%$ \\
\hline
\end{tabular}

Fonte: Cristina Rolim Wolffenbüttel.

Dos municípios que fizeram concursos houve o ingresso de aproximadamente 71 professores de música nas redes públicas municipais do RS. Este ingresso foi implementado de diferentes modos. Alguns municípios contrataram apenas um professor, outros municípios efetuaram o contrato com mais de um professor de Música. A Tabela 6, a seguir, apresenta os ingressos dos professores de Música através de concursos públicos no Rio Grande do Sul.

Tabela 6: Ingresso de Professores de Música através de Concursos nos Municípios.

\begin{tabular}{|l|c|c|}
\hline \multicolumn{1}{|c|}{ Tipo de Atividade Musical } & Número de Municípios & $\%$ \\
\hline Ingresso de 1 professor de música. & 19 & $38,77 \%$ \\
\hline Ingresso de mais de 5 professores de música. & 04 & $8,16 \%$ \\
\hline Ingresso de 3 professores de música. & 04 & $8,16 \%$ \\
\hline Ingresso de 2 professores de música. & 03 & $6,12 \%$ \\
\hline Ingresso de 5 professores de música. & 02 & $4,08 \%$ \\
\hline Ingresso de 4 professores de música. & 01 & $2,04 \%$ \\
\hline
\end{tabular}

Fonte: Cristina Rolim Wolffenbüttel.

Algumas secretarias municipais de educação deixaram de informar o número de professores que ingressaram em suas redes públicas de ensino, não sendo possível computá-los neste panorama geral aqui apresentado. 


\subsection{Os profissionais que desenvolvem atividades musicais nas escolas}

Como explicado anteriormente, apesar da não realização de concursos públicos pela maioria dos municípios, as secretarias municipais de educação informaram que desenvolvem atividades musicais nas escolas de suas redes de ensino. Esta informação deve-se ao fato de a educação musical ser exercida por diversos profissionais que, muitas vezes, não são professores de Música concursados.

Ao serem questionadas sobre quem são os profissionais que atuam com Música nas escolas, as secretarias municipais de educação apontaram uma diversidade de profissionais, inclusive os professores de Música. Nas respostas das secretarias municipais de educação quanto aos profissionais que atuam com Música nas escolas destacaram-se professores das séries/anos iniciais ou titulares das turmas, oficineiros contratados através de empresas para a prestação deste serviço, professores de artes, professores que tocam instrumentos musicais ou que têm alguma experiência em educação musical, mas sem estudos formais em música, instrutores de banda e/ou coral, professores que atuam com outras áreas do conhecimento e oficineiros do Programa Mais Educação.

Além destes profissionais, outros também apareceram nas respostas dos questionários. A Tabela 7 completa com os profissionais que desenvolvem atividades musicais nas escolas das redes públicas municipais do RS é apresentada a seguir.

Tabela 7: Profissionais que Desenvolvem Atividades Musicais nas Escolas Públicas Municipais.

\begin{tabular}{|l|c|}
\hline \multicolumn{1}{|c|}{ Profissionais que trabalham com música nas escolas } & $\%$ \\
\hline Professores das séries/anos iniciais, ou titulares das turmas. & $19,62 \%$ \\
\hline Oficineiros contratados através de empresas para a prestação de serviço. & $18,88 \%$ \\
\hline Professores de Artes. & $18,14 \%$ \\
\hline $\begin{array}{l}\text { Professores que tocam instrumentos musicais, ou que têm alguma experiência em educação musical, mas não possuem } \\
\text { licenciatura em música. }\end{array}$ & $15,18 \%$ \\
\hline Instrutores de banda e/ou coro. & $11,11 \%$ \\
\hline Professores que atuam com outras áreas do conhecimento. & $10,37 \%$ \\
\hline Oficineiros do Programa Mais Educação. & $10 \%$ \\
\hline Professores e/ou monitores da Educação Infantil. & $6,66 \%$ \\
\hline Professores não concursados em música. & $5,18 \%$ \\
\hline Professores concursados em música. & $5,18 \%$ \\
\hline Voluntários. & $2,96 \%$ \\
\hline Professores com licenciatura em música. & $2,96 \%$ \\
\hline Professores que atuam através da Secretaria Municipal de Cultura. & $1,11 \%$ \\
\hline Licenciandos dos cursos de graduação em música. & $1,11 \%$ \\
\hline Professores itinerantes da escola. & $0,37 \%$ \\
\hline Professores de dança. & $0,37 \%$ \\
\hline Professores contratados com cargos de confiança. & $0,37 \%$ \\
\hline Oficineiros do Programa Escola Aberta. & $0,37 \%$ \\
\hline Oficineiros dos Centros de Referência da Assistência Social (CRAS). & $0,37 \%$ \\
\hline
\end{tabular}

Fonte: Cristina Rolim Wolffenbüttel.

\section{Conclusões}

Após a apresentação dos resultados e da análise dos dados, faz-se uma síntese dos mesmos, com vistas a destacar padrões encontrados na pesquisa e as relações existentes entre as categorias identificadas. Pretende-se, assim, construir um quadro mais amplo da presença do ensino da Música em escolas públicas municipais do Rio Grande 
do Sul, respondendo aos questionamentos desta investigação e alcançando-se o objetivo nela proposto.

O retorno dos questionários pelas secretarias municipais de educação pode ser analisado de dois modos. Por um lado, o número de respostas foi significativo para a análise dos dados. Por outro lado, no entanto, deve-se salientar a problemática do não retorno dos questionários por parte de 227 instituições públicas. Neste sentido, há que se considerar a existência do Decreto $n^{0} 7.724$, de 2012 (BRASIL, 2012), que regulamenta a Lei $\mathrm{n}^{0} 12.527$, de 2011, sobre o acesso às informações no Brasil. Neste decreto encontra-se expresso no Artigo $7^{\circ}$, capítulo III - da Transparência Ativa - que é dever dos órgãos e entidades promover, independente de requerimento, a divulgação em seus sítios na Internet de informações de interesse coletivo ou geral por eles produzidas ou custodiadas. O parágrafo $3^{\circ}$ do mesmo decreto especifica, inclusive, o dever de divulgar estrutura organizacional, competências, legislação aplicável, principais cargos e seus ocupantes, endereço e telefones das unidades, horários de atendimento ao público, programas, projetos, ações, obras e atividades, com indicação da unidade responsável, principais metas e resultados e, quando existentes, indicadores de resultados e impactos. Percebe-se, novamente, o descumprimento da legislação vigente. Sabe-se que, muitas vezes, os órgãos públicos têm insuficiência de funcionários, resultando dificuldades na produção e no acesso às informações, por não existir pessoal em número suficiente para a elaboração das respostas requeridas. Mas, de todo o modo, é outro dado que revela o não cumprimento da legislação vigente e considera-se pertinente a busca de soluções para este problema.

Em se tratando da oferta de atividades musicais nas escolas, se for analisada superficialmente, pode-se dizer que as secretarias municipais de educação do RS estão ofertando a Música em seus tempos e espaços. Neste caso, a legislação (BRASIL, 2008) está sendo cumprida. Mas, se a análise for mais abrangente e aprofundada e, levando-se em consideração a Resolução n ${ }^{\circ}$ 2, de 10 de maio de 2016, que define as Diretrizes Nacionais para a operacionalização do ensino de Música na Educação Básica (BRASIL, 2016), o cumprimento não está adequado. Vale salientar, ainda, com base nas diretrizes, que compete às secretarias de educação estabelecer outras ações para promover a formação e a prática de docentes no ensino de Música, identificando "em seus quadros de magistério e de servidores, profissionais vocacionados que possam colaborar com o ensino de Música nas escolas, incluindo-os nas atividades de desenvolvimento profissional na área de música” (BRASIL, 2016; BRASIL, 2013). Adicionalmente, as redes de ensino devem, também, "promover cursos de formação continuada sobre o ensino de Música para professores das redes de escolas da Educação Básica; [e] apoiar a formação dos professores e dos demais profissionais da educação em cursos de segunda licenciatura em Música” (BRASIL, 2013, p. 9). De um modo geral, nos questionários respondidos não foram apontadas iniciativas neste sentido por parte das secretarias municipais de educação no RS.

Um aspecto peculiar a ser analisado relaciona-se às atividades musicais existentes nas escolas. Estes dados estão em sintonia com a análise apresentada anteriormente, relativa à oferta de atividades musicais nas escolas. Na sua maioria, a Música está presente nas escolas através de atividades que não as aulas de música no currículo. Muitas vezes, são atividades musicais extracurriculares desenvolvidas por profissionais não pertencentes aos quadros de professores das escolas, atividades vinculadas a projetos, inclusive, momentâneos, que podem ser finalizados de acordo com as gestões governamentais. São atividades, em geral, que se caracterizam como programas de governo, e não como programas de estado. Com índices menos elevados foi encontrada a oferta de aulas de Música como disciplina específica, separada da Educação Artística ou de outras atividades. 
A realização dos concursos públicos para professores de música é um item que, também, merece análise e reflexão. Novamente, apresentou-se o descumprimento da legislação. Deve-se destacar, nas Diretrizes Nacionais para a Operacionalização do Ensino de Música na Educação Básica, que uma das atribuições das secretarias é a de "realizar concursos específicos para a contratação de licenciados em Música” (BRASIL, 2013, p. 9). Outra ausência de ações neste sentido e do descumprimento da legislação foram verificados nesta pesquisa. Como consequência da não realização de concursos, as últimas categorias de análise - presença de professores de Música e profissionais que desenvolvem atividades musicais nas escolas - relacionam-se. O número de professores de Música concursados e atuantes nas escolas públicas municipais do RS é reduzido. E, efetivamente, quem acaba desenvolvendo este tipo de atividade, são professores de outras áreas do conhecimento, ou mesmo profissionais que não os da escola, mas oriundos de diversos projetos ou ações.

Ao finalizar esta pesquisa, que objetivou investigar presença do ensino da Música em escolas públicas municipais do RS, constou-se a realidade da Música nas escolas do RS, bem como a relevância do referencial teórico utilizado. A concepção de educação musical, fundamentada em Kraemer (2000), auxiliou no entendimento de como a Música se insere nas escolas, ao passo que a Abordagem do Ciclo de Políticas (BOWE et al, 1992; BALL, 1994) balizou a análise da política em vigor.

Entende-se que os resultados desta investigação, bem como os dados de outras pesquisas que têm sido empreendidas no RS e no Brasil, poderão subsidiar macro e microanálises das políticas em educação musical no Brasil, bem como fundamentar e ampliar a construção de políticas públicas para a implementação da Música nas escolas brasileiras. A problematização que a Abordagem do Ciclo das Políticas propõe, em interlocução com os conceitos de educação musical, podem auxiliar no aprofundamento destas análises sobre a legislação para a inserção da música na Educação Básica.

Por fim, aponta-se a necessidade do conhecimento e da compreensão da legislação existente por parte das secretarias de educação, a fim de que seja, efetivamente, cumprida a lei da inserção da Música nas escolas e toda a legislação em educação vigente no Brasil.

\section{Notas}

1 O Programa Mais Educação foi instituído pela Portaria Interministerial no 17/2007 e regulamentado pelo Decreto 7.083/10. Foi uma estratégia do Ministério da Educação no Brasil para ampliar jornada escolar e a organização curricular na perspectiva da Educação Integral. As escolas das redes públicas de ensino estaduais, municipais e do Distrito Federal fazem a adesão ao Programa e, de acordo com o projeto educativo em curso, optam por desenvolver atividades nos macrocampos de acompanhamento pedagógico; educação ambiental; esporte e lazer; direitos humanos em educação; cultura e artes; cultura digital; promoção da saúde; comunicação e uso de mídias; investigação no campo das ciências da natureza e educação econômica. As atividades musicais são possibilidades de atividades no macrocampo cultura e artes.

2 Dados obtidos junto à Secretaria da Educação, por meio do site http://www.educacao.rs.gov.br/pse/html/busca_ escolas.jsp.

3 Programa em cooperação técnica entre o Ministério da Educação e a Unesco, objetiva contribuir para a melhoria da qualidade da educação, a inclusão social e a construção de uma cultura de paz, por meio da ampliação da integração entre escola e comunidade; ampliação das oportunidades de acesso à formação para a cidadania e redução de violências na comunidade escolar. Visa proporcionar aos alunos da Educação Básica de escolas públicas e às suas comunidades, espaços alternativos nos finais de semana para o desenvolvimento de atividades de cultura, esporte, lazer, geração de renda, formação para a cidadania e ações complementares às de educação formal. As atividades musicais são fortemente desenvolvidas neste programa. 


\section{Referências}

BABBIE, Earl. Métodos de pesquisas de survey. Belo Horizonte: Ed. da UFMG, 1999.

BALL, Stephen J. Educational reform: a critical and post structural approach. Buckingham: Open University Press, 1994.

BOWE, Richard et al. Reforming education and changing schools: case studies in policy sociology. London: Routledge, 1992.

BRASIL. Conselho Nacional de Educação/Câmara de Educação Básica. Resolução CNE/CEB 2/2016. Define Diretrizes Nacionais para a operacionalização do ensino de Música na Educação Básica. Diário Oficial, Brasília, DF, 11 mai. 2016. Seção 1, p. 42. Disponível em: http://www.jusbrasil.com. br/diarios/115500193/dou-secao-1-11-05-2016-pg-42/pdfView. Acesso em: 28 de junho de 2016.

. Conselho Nacional de Educação/Câmara de Educação Básica. Parecer $n^{o}$ 12/13, de 4 de dezembro de 2013, do CNE. Sobre Diretrizes Nacionais para a operacionalização do ensino de Música na Educação Básica. Disponível em: http://portal.mec.gov.br/index.php?option=com_ docman\&view=download\&alias=14875-pceb012-13\&category_slug=dezembro-2013pdf\&Itemid=30192. Acesso em: 29 de janeiro de 2016.

. Casa Civil. Subchefia de Assuntos Jurídicos. Decreto no 7.724, de 16 de maio de 2012. Regulamenta a Lei $\mathrm{n}^{0} 12.527$, de 18 de novembro de 2011, que dispõe sobre o acesso a informações previsto no inciso XXXIII do caput do art. $5^{\circ}$, no inciso II do $\S 3^{\circ}$ do art. 37 e no $\S 2^{\circ}$ do art. 216 da Constituição. Disponível em: http://www.planalto.gov.br/ccivil_03/_ato2011-2014/2012/ decreto/d7724.htm. Acesso em: 28 de janeiro de 2016.

. Diário Oficial da União. Lei $n^{o} 11.769$ de 18 de agosto de 2008. Altera a Lei no 9394/96, para dispor sobre a obrigatoriedade do ensino de música na educação básica. Seção 1. Brasília: Imprensa Nacional, 2008. Disponível em: http://www.planalto.gov.br/ccivil_03/_ato20072010/2008/lei/l11769.htm. Acesso em: 27 de janeiro de 2016.

. Lei $n^{o}$ 9.394, de 20 de dezembro de 1996. Estabelece as Diretrizes e Bases da Educação Nacional. Brasília, 1996. Disponível em: http://www.planalto.gov.br/ccivil_03/LEIS/L9394.htm. Acesso em: 29 de janeiro de 2016.

. Câmara dos Deputados. Lei $n^{o}$ 6.448, de 11 de outubro de 1977(a). Dispõe sobre a organização política e administrativa dos Municípios dos Territórios Federais, e dá outras providências. 1977. Disponível em: http://www2.camara.leg.br/legin/fed/lei/1970-1979/lei-6448-11-outubro-1977-366388-normaatualizada-pl.pdf. Acesso em: 29 de janeiro de 2016.

. Conselho Federal de Educação. Parecer $n^{\circ}$ 540/77, de 10 de fevereiro de 1977(b), do CFE. Sobre o tratamento a ser dado aos componentes curriculares previstos no art. $7^{\circ}$ da Lei $\mathrm{n}^{\mathrm{o}}$ 5.692/71. Disponível em: http://www.histedbr.fe.unicamp.br/navegando/fontes_escritas/7_Gov_ Militar/parecer\%20n.\%20540-1977\%20sobre\%20o\%20tratamento\%20a\%20ser\%20dado\%20 aos\%20comp\%20curriculares.pdf. Acesso em: 29 de janeiro de 2016.

BRASIL. Conselho Federal de Educação. Parecer n $n^{\circ}$ 1.284, de 1973. Secretaria de Ensino de Primeiro e Segundo Graus. Educação artística: leis e pareceres. Brasília, 1973, incluindo a resolução CFE n ${ }^{0} 23 / 73$.

. Lei $n^{\circ}$ 5.692, de 11 de agosto de 1971. Fixa as Diretrizes e Bases da educação para o ensino de $1^{\circ}$ e $2^{\circ}$ graus e dá providências. Brasília, 1971. Disponível em: http://www.planalto.gov. br/CCIVIL_03/leis/L5692.htm. Acesso em: 29 de janeiro de 2016.

COHEN, Louis; MANION, Lawrence. Research methods in education. London: Routledge. 4. ed, 1994. 
DEL BEN, Luciana Marta. Um estudo com escolas da rede estadual de ensino básico de Porto Alegre - RS: subsídios para a elaboração de políticas de educação musical. Musica Hodie, v. 5, n. 2, 2005, p. 65-89. Disponível em: http://www.musicahodie.mus.br/5_2/musica_hodie_5_2_artigo_5.pdf. Acesso em: 5 de fevereiro de 2015.

DINIZ, Leila Negrini. Música na educação infantil: um survey com professoras da rede municipal de ensino de Porto Alegre - RS. 2005. Dissertação (Mestrado em Música) - Programa de PósGraduação Mestrado e Doutorado em Música, Instituto de Artes, Universidade Federal do Rio Grande do Sul, Porto Alegre, 2005.

HENTSCHKE, Liane; OLIVEIRA, Alda. A educação musical no Brasil. In: HENTSCHKE, Liane (Org.). Educação musical em países de línguas neolatinas. Porto Alegre: Ed. Universidade/UFRGS, 2000. p. 47-64.

KRAEMER, Rudolf-Dieter. Dimensões e funções do conhecimento pedagógico-musical. Em Pauta, Porto Alegre, v. 11, n. 16/17, abr./nov., p. 50-73, 2000.

LAVILLE, Christian; DIONNE, Jean. A construção do saber: manual de metodologia da pesquisa em ciências humanas. Porto Alegre: Artes Médicas Sul; Belo Horizonte: Editora UFMG, 1999.

LEMOS JÚNIOR, Wilson. História da educação musical e a experiência do canto orfeônico no Brasil. EccoS - Rev. Cient., São Paulo, n. 27, p. 67-80, jan./abr. 2012. p. 67-80. Disponível em: http://www.redalyc.org/pdf/715/71523347005.pdf. Acesso em: 5 de fevereiro de 2015.

MARCONI, Marina de Andrade; LAKATOS, Eva Maria. Fundamentos de metodologia científica. 6. ed. São Paulo: Atlas, 2005.

MORAES, Roque. Análise de conteúdo. Educação, Porto Alegre: Pontifícia Universidade Católica do Rio Grande do Sul, ano XXII, n. 37, p. 7-31, março 1999.

PENNA, Maura. Música no Programa Mais Educação: Discutindo a Diversidade das Práticas. Revista Música Hodie, Goiânia, v. 14, n. 2, 2014, p. 84-98. Disponível em: http://www.musicahodie.mus.br/14.2/17_Arrtigo\%20Cientifico_142.pdf. Acesso em: 28 de junho de 2016.

. A dupla dimensão da política educacional e a música na escola: - I analisando a legislação e os termos normativos. Revista da ABEM, Porto Alegre, v. 10, mar. 2004a, p. 19-28.

. A dupla dimensão da política educacional e a música na escola: - II da legislação à prática escolar. Revista da ABEM, Porto Alegre, v. 11, set. 2004b, p. 7-16.

PENNA, Maura. Professores de música nas escolas públicas de ensino fundamental e médio: uma ausência significativa. Revista da ABEM, Porto Alegre, v. 7, set. 2002, p. 7-19.

QUEIROZ, Luis Ricardo Silva. A educação musical no Brasil do século XXI: articulações do ensino de música com as políticas brasileiras de avaliação educacional. Revista da ABEM, Londrina, v. 20 , n. 28, dec. 2013. p. 35-46. Disponível em: <http://www.abemeducacaomusical.com.br/revistas/revistaabem/index.php/revistaabem/article/view/102/85>. Acesso em: 28 de junho de 2016.

. Música na escola: aspectos históricos da legislação nacional e perspectivas atuais a partir da Lei 11.769/2008. Revista da Abem, Londrina, v. 20, n. 29, jul./dez., 2012, p. 23-38.

QUEIROZ, Luis Ricardo Silva; PENNA, Maura. Políticas públicas para a Educação Básica e suas implicações para o ensino de música. Educação, Santa Maria, v. 37, n. 1, p. 91-106, jan./abr. 2012.

REQUIÃO, Luciana. Música nas escolas: mercadoria ou formação humana? Educação: Teoria e Prática, Rio Claro, v. 23, n. 43/ p. 169-181/ Mai-Ago. 2013. Disponível em: http://educa.fcc.org.br/ pdf/eduteo/v23n43/v23n43a11.pdf. Acesso em: 4 de fevereiro de 2015.

SANTOS, Regina Márcia Simão. Música, a realidade nas escolas e políticas de formação. Revista da ABEM, Porto Alegre, v. 12, mar, 2005, p. 49-56. 
SOUZA, Jusamara Vieira et al. A música na escola. In: O que faz a música na escola? Concepções e vivências de professores do ensino fundamental. Série Estudos. Porto Alegre, novembro de 2002.

VEBER, Andréia. A escola de tempo integral: um espaço potencial para as aulas de música na educação básica. Revista da ABEM, Londrina, v. 20, n. 29, p. 23-38, jul./dez., 2012.

WOLFFENBÜTTEL, Cristina Rolim. A inserção da música em projetos político pedagógicos da educação básica. Curitiba: Prismas, 2014.

. Ensino de música na educação básica: uma investigação em escolas públicas do Rio Grande do Sul. XXI Congresso da ANPPOM, 2011, Uberlândia. Anais... Uberlândia: 2011, p. 335-340.

WOLFFENBÜTTEL, Cristina Rolim; ERTEL, Daniele Isabel. O ensino de música no Rio Grande do Sul: investigando escolas públicas do estado. In: CONGRESSO NACIONAL DA ASSOCIAÇÃO BRASILEIRA DE EDUCAÇÃO MUSICAL, 20., 2011, Vitória. Anais... Vitória: ABEM, 2011. p. $1665-1674$.

WOLFFENBÜTTEL, Cristina Rolim; SILVA, Patrick da Costa. O ensino de música no litoral do Rio Grande do Sul: uma pesquisa sobre educação musical em escolas públicas municipais. XVI Encontro Regional Sul da ABEM, Anais... 2014, p. 1-12.

Cristina Rolim Wolffenbüttel - Pós-Doutora, Doutora e Mestre em Educação Musical pela Universidade Federal do Rio Grande do Sul; Especialista em Informática na Educação Ênfase em Instrumentação, pela Pontifícia Universidade Católica do Rio Grande do Sul. Licenciada em Música pela Universidade Federal do Rio Grande do Sul. Coordena o curso de Especialização em Educação Musical na Universidade Estadual do Rio Grande do Sul, Unidade de Montenegro. É coordenadora de Área-Música do Programa de Bolsa de Iniciação à Docência (PIBID), em Montenegro, da CAPES/UERGS. Coordena a Comissão de Pesquisa e Pós-Graduação da Uergs-Montenegro, orientando bolsistas de iniciação científica em música e artes, da FAPERGS, CNPq e UERGS. É coordenadora dos grupos de pesquisa registrados no CNPq Arte: criação, interdisciplinaridade e educação e Educação Musical: diferentes tempos e espaços. Coordena o Programa de Extensão Universitária, do Ministério da Educação, pela Uergs, na temática da ampliação da leitura através das Artes, desenvolvendo ações de leitura com estudantes bolsistas, beneficiando as redes públicas municipais e estaduais de Porto Alegre e Montenegro. Na Prefeitura de Porto Alegre, a partir da atuação na Secretaria Municipal de Educação, é assessora pedagógica e coordenadora dos programas Centros de Dança e Brinca, propondo e desenvolvendo políticas públicas para a inserção das artes nas escolas da Rede Municipal de Ensino de Porto Alegre. Criou, em conjunto com colegas professores da rede municipal de Porto Alegre, o Programa Centros Musicais, uma proposta de política pública para o ensino de música na escola, em vigor na Secretaria Municipal de Educação do município, o qual coordena desde sua criação. É Diretora Científica da Coleção Educação Musical, da Editora Prismas, de Curitiba. Faz parte da Associação Brasileira de Educação Musical, da Comissão Gaúcha de Folclore e da Fundação Santos Herrmann. Recebeu o Prêmio Jovem Pesquisador, pela Universidade Federal do Rio Grande do Sul, em 1988, com a pesquisa Acalantos, orientada pela Prof ${ }^{a} \mathrm{Dr}^{\mathrm{a}}$ Rose Marie Reis Garcia, com o objetivo de resgatar as cantigas de ninar. Em 2010 recebeu, do Comitê de Entidades no Combate à Fome e pela Vida (COEP), o Prêmio Betinho Atitude Cidadã, um reconhecimento às ações em música desenvolvidas junto às escolas de Porto Alegre, potencializando o projeto do COEP de luta contra a fome e pela promoção da cidadania. Recebeu a Medalha Dante de Laytano, em 2011, em reconhecimento aos relevantes serviços prestados para a preservação, promoção, pesquisa e defesa do folclore e das manifestações culturais tradicionais populares do Rio Grande do Sul. Em 2013 recebeu o Troféu Mulher Gaúcha, da Secretaria de Políticas para as Mulheres/SPM-RS, pelo conjunto da obra na área da pesquisa em folclore e educação musical. Presidente da Academia Montenegrina de Letras, ocupando a Cadeira nº5, e da Associação Montenegrina de Escritores. Dentre sua produção científica destacam-se publicações individuais e com parcerias. É autora dos livros A Inserção da Música em Projetos Político Pedagógicos da Educação Básica, A Música na Região de Montenegro, Cantigas de Ninar, Terço Cantado: a religiosidade popular na Região de Montenegro, Resgatando os Contos e as Lendas da Nossa Terra, além de artigos sobre Música, Educação Musical e Cultura Popular em revistas e periódicos especializados. Em parcerias, escreveu o livro Música para Professores: experiências de formação continuada, juntamente com Jusamara Souza e Liane Hentschke; O Ensino das Artes, com Maria Aparecida A. Marques; Para Compreender e Aplicar Folclore na Escola, com Rose Marie Reis Garcia. No campo artístico atuou em Porto Alegre como violinista na Orquestra do Centro Cultural 25 de Julho e como regente do Coral do Colégio Sévigné. Em Montenegro foi regente do Grupo de Canto Gregoriano Vox Noctis e do Coral da Fundarte. Na cidade de Gravataí foi regente dos coros infantil e adulto. É verbete no Dicionário de Mulheres, da autoria de Hilda Agnes Hubner Flores. 
Daniele Isabel Ertel - Professora de Música, Pós-graduada em Serviços Sociais, Ética e Direitos Humanos pela AVM Faculdade Integrada, Pós-graduanda Educação Musical pela Universidade Estadual do Rio Grande do Sul. Graduada em Licenciatura em Música, pela Universidade Estadual do Rio Grande do Sul. Integrante do Grupo de Pesquisa "Educação Musical: diferentes tempos e espaços; (CNPq/UERGS). Atua no ensino de música na Educação Infantil e Ensino Fundamental junto a escolas da Rede Pública Municipal de Porto Alegre/RS e São Pedro da Serra/RS. Professora e proprietária do Espaço Mãos Mágicas, escola particular de música que oferece formação musical em diversos instrumentos musicais para os munícipes de Salvador do Sul/RS.

Jusamara Vieira Souza - Doutora e Mestre em Educação Musical pela Universität Bremen, Alemanha, é Professora Titular do Departamento de Música, Instituto de Artes da Universidade Federal do Rio Grande do Sul - UFRGS. Desde 1997 tem atuado como professora no curso de Licenciatura em Música e orientadora de Mestrado e Doutorado no Programa de Pós-Graduação em Música da UFRGS. Foi Presidente da Associação Brasileira de Educação Musical (ABEM) nos períodos 2001-2003 e 2003-2005. De 2000 a 2006 atuou como Editora da Revista em Pauta publicada pelo Programa de Pós-Graduação em Música da UFRGS. Foi Diretora da Editora da UFRGS (2002-2008) e Coordenadora Substituta do Programa de Pós-Graduação em Música da UFRGS (2009-2011). Tem desenvolvido vários projetos de Extensão na área de Educação Musical incluindo a Coordenação Geral do Projeto de Extensão \&quot;Música nas Escolas do Rio Grande do Sul: Um Programa de Formação Continuada para Professores das Redes Públicas\&quot; (2014-2016), financiado pelo FNDE/ MEC. Pesquisadora Nível 1 do CNPq, coordena o Grupo de Pesquisa Educação Musical e Cotidiano (EMCO), criado em 1996 e registrado no Diretório de Grupo de Pesquisa do CNPq. Suas pesquisas e publicações na área de música incluem os campos da sociologia e epistemologia da educação musical abordando temas como: aprendizagem e ensino de música no cotidiano, socialização musical e juventudes, música na escola e a construção da área de educação musical. Possui inúmeros artigos científicos, capítulos de livros, livros e ministrou diversas conferências, palestras e cursos no Brasil, Argentina, Chile, México, Espanha, Portugal e Alemanha. Possui ainda inúmeros trabalhos apresentados em Congressos Nacionais e Internacionais. Pela sua experiência na área tem atuado como consultora em diversos órgãos governamentais de apoio à pesquisa como FAPERGS, FAPESP, CAPES e CNPQ. 